\title{
Diel behaviour and habitat utilisation by the pearly razorfish during the spawning season
}

\author{
J. Alós ${ }^{1, *}$, M. Cabanellas-Reboredo ${ }^{1}$, S. Lowerre-Barbieri ${ }^{2}$ \\ ${ }^{1}$ Instituto Mediterráneo de Estudios Avanzados (IMEDEA; CSIC-UIB), Miquel Marqués, 21, Esporles, \\ Illes Balears 07008, Spain
}

${ }^{2}$ Florida Fish and Wildlife Conservation Commission, Fish and Wildlife Research Institute, St. Petersburg, Florida 33701, USA

\begin{abstract}
Despite its small size, the pearly razorfish Xyrichtys novacula (Linnaeus, 1758) supports important targeted recreational and commercial fisheries. Here, we present the first data on the movements of this species obtained using acoustic telemetry in a temperate marine protected area (MPA). The results demonstrate that acoustic telemetry is well suited for behavioural studies, even in species of small size. The results confirmed previous speculations regarding the behaviour of this species, demonstrating a clear diel pattern with maximum rates of activity during the day and fewer detections at night, when the fish bury themselves in the soft bottom. $X$. novacula exhibited a sedentary lifestyle with limited movement. The fish occurred in an accumulated averaged area of $0.32 \pm 0.13 \mathrm{~km}^{2} 95 \%$ of the time (95\% kernel utilisation distribution [KUD]) and in a core area ( $50 \% \mathrm{KUD})$ of $0.07 \pm 0.02 \mathrm{~km}^{2}$. These small areas of habitat utilisation existed independent of sex and diel behaviour. No daily migration pattern or specific resting locations were detected. The linearity index (as a proxy of site fidelity) demonstrated that the movement of $X$. novacula was random within a specific home range area (sedentary behaviour) rather than directional (nomadic behaviour). The observed diel pattern of behaviour confirms that this species is not vulnerable to nighttime fishing, and the small spatial scale of habitat utilisation suggests that small MPAs can be an effective management tool.
\end{abstract}

KEY WORDS: Acoustic telemetry - Continuous wavelet transform · Control tag · Home range · MPA $\cdot$ Protogynous hermaphrodite $\cdot$ Xyrichtys novacula

Resale or republication not permitted without written consent of the publisher

\section{INTRODUCTION}

The pearly razorfish Xyrichtys novacula (Linnaeus, 1758 ) is one of the species most targeted by Mediterranean fishers, especially recreational fishers (Morales-Nin et al. 2005, 2010). This labrid exhibits a wide spatial distribution range including the Western Atlantic (from North Carolina [USA] to the north of the Gulf of Mexico and from the Caribbean to Brazil), Eastern Atlantic (from the southern coast of Spain to the south of Cape Lopez, Gabon), Mediterranean, Azores, Madeira, Canary Islands, Cape Verde and Sao Tome Island (Froese \& Pauly 2005).
Xyrichtys novacula is a protogynous monandric hermaphrodite with marked sexual dimorphism (Marconato et al. 1995, Candi et al. 2004), a relatively short lifespan (8 yr; Froese \& Pauly 2005) and a maximum total length of $320 \mathrm{~mm}$ (Froese \& Pauly 2005). Sex inversion or transition typically occurs at $79 \%$ of the fish's maximum size (Linde \& Palmer 2008), and spawning occurs in the warm season, with a peak in August (Cardinale et al. 1998). The preferred habitats of this species are coarse or very coarse unvegetated sandy bottoms (Katsanevakis 2005) or soft bottoms vegetated by Cymodocea nodosa meadows (Tuya et al. 2005), where it feeds on small benthic 
prey (Cardinale et al. 1997, Castriota et al. 2005a,b), occupying a mid-trophic level within the food web (Blanco et al. 2009, Box et al. 2010).

Some populations of this species have been subjected to overfishing, exhibiting clear decreases in abundance and their age and size distributions as well as the size at maturation, thereby decreasing the size at sex change and affecting reproductive output (Linde \& Palmer 2008). In an effort to effectively manage this species, a number of management measures have been adopted, including seasonal closures, daily bag limits and minimum sizes of hooks (e.g. Morales-Nin et al. 2010).

However, the usefulness of MPAs depends on the scale of fish movement in relation to the size of the MPA (Kramer \& Chapman 1999). Thus, effective MPAs must include appropriate habitats and be sufficiently large to encompass the regular movements of adult fish (i.e. their home ranges). Then, the spillover of early life stages (eggs and larvae) and the movement of adults into areas outside the MPA can only be successful (in terms of sustainability) if a stable adult population is able to persist within the protected area (Kaplan et al. 2006).

Unfortunately, most management measures continue to be based on the assumption that fish populations are spatially homogeneous (Botsford et al. 2009). However, catchability is clearly impacted by a species' underlying spatio-temporal behaviour, and knowledge of this behaviour is needed to improve decision-making processes (Botsford et al. 2003). This is the case for Xyrichtys novacula, for which little is known about its spatio-temporal movement patterns. In this context, acoustic telemetry is considered to represent an alternative to conventional tagand-recapture studies for assessing individual fish movement, allowing us to improve existing knowledge of the spatial and temporal structure of fish species over various scales of space and time (Voegeli et al. 2001, Parsons \& Egli 2005). The resulting improvements in experimental design (Heupel et al. 2006) and the development of new algorithms to support improved location of fish (Hedger et al. 2008) linked to the miniaturisation of acoustic tags make this methodology highly desirable for investigating spatial and temporal patterns in marine coastal fisheries. Thus, the main objective of the present study was to provide a first approach to identify the spatio-temporal behaviour of $X$. novacula using acoustic telemetry during the spawning season, specifically by assessing the home ranges and movement patterns of these fish during day versus nighttime hours. The implications of the results for management, such as de- termining the size of an MPA to effectively protect this species, were also explored and directly linked to the sustainable development of the fishery of this species.

\section{MATERIALS AND METHODS}

\section{Study site and acoustic receiver array}

The MPA of Palma Bay is located to the south of Mallorca Island (NW Mediterranean; Fig. 1). Fishing activities in the MPA have been regulated since 1982 (Fisheries Department, Balearic Islands Government), and it contains 2 main areas with different degrees of protection: a no-take area $\left(\sim 2 \mathrm{~km}^{2}\right)$ and a buffer area where both artisanal and recreational fishing are regulated (e.g. gear limitations or temporal closures) but not prohibited. The main habitat in the MPA is characterised by the endemic Mediterranean seagrass Posidonia oceanica (Fig. 1). However, the southern buffer area is dominated by fine sand (grain size from 0.125 to $0.250 \mathrm{~mm}$ ) and coarse sand (grain size from 0.5 to $1 \mathrm{~mm}$ ) bottoms, representing optimal habitat for Xyrichtys novacula (Katsanevakis 2005; Fig. 1).

In July 2011, a fixed array of 21 omni-directional acoustic receivers (model SUR-1, Sonotronics) was deployed in the southern area of the MPA, covering most of the soft bottom habitat (Fig. 1). Prior to deploying the receivers, the detection range of the tags to be used in the present study was assessed by mooring a number of tags at different distances from a receiver. The maximum detection range was $>300 \mathrm{~m}$ (see details in Fig. 2). Thus, the receiver array, based on a $300 \times 300 \mathrm{~m}$ grid, provided a high degree of detection overlap between receivers (see Fig. 1), allowing improved centre of activity estimations (Simpfendorfer et al. 2002).

\section{Tagging procedures}

After the receiver arrays were deployed, $12 X Y$ richtys novacula individuals were acoustically tagged using Pico-tags (model PT-2, Sonotronics). The miniaturised tags measured $19 \mathrm{~mm}$ in length and $7.1 \mathrm{~mm}$ in diameter, weighed $1 \mathrm{~g}$ in water and did not exceed $2 \%$ of the fish's body weight (Table 1 ). The tags had a manufacturer's expected lifespan of $12 \mathrm{~d}$. However, the true lifespan of the acoustic tags was considerably longer (see 'Results'). Each tag emitted a specific sequence of pulses at a given frequency (70 


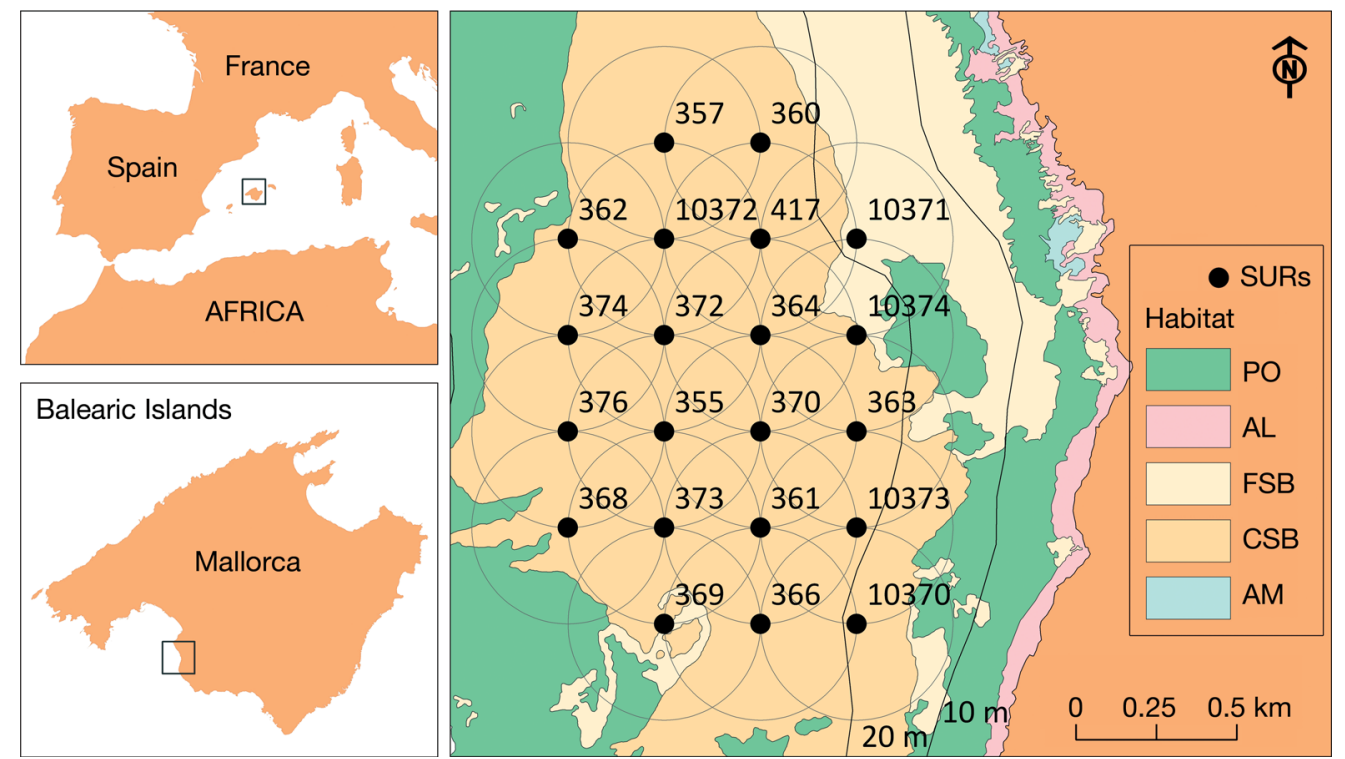

Fig. 1. Study site located in the marine protected area of Palma Bay, Mallorca Island (NW Mediterranean). The figure shows the omni-directional acoustic receivers (SUR-1) array detailing the ID receiver as well as a buffer area (detection range) of $300 \mathrm{~m}$ of radius. Habitat types are named as Posidonia oceanica seagrasses (PO), rocky bottoms with photophilous algae (AL), fine sand bottoms (FSB), coarse sand bottoms (CSB), and a mixture of algae and seagrasses (AM)

to $82 \mathrm{kHz}$ ), allowing individual fish to be identified (Table 1). The tags were programmed to emit signals every $1200 \mathrm{~ms}$. When a receiver detected a signal, it was recorded as a single detection, which was labelled with a detection number and the date, hour, frequency $(\mathrm{kHz})$ and interval period $(\mathrm{ms})$.

All individuals were caught inside the fixed array by anglers at depths ranging from 22 to $25 \mathrm{~m}$ using conventional hook-and-line gear and small live shrimps as bait. Performing the tag-and-release of all individuals on the same day optimised the modelling procedures, allowing us to include the daily variation in the detection pattern in the model (see 'Data analysis'). Angling sessions were optimised to reduce the incidence of deep hooking and barotrauma effects, following published recommendations (Alós 2008, Alós et al. 2008, 2009). The tagging was performed in the spawning season (Cardinale et al. 1998), 7 males and 5 females were tagged to test sexrelated differences in temporal and spatial patterns (Table 1).

The fish were measured (total length to the nearest $\mathrm{mm}$ ), weighed (to the nearest $\mathrm{g}$ ) and placed in a $150 \mathrm{l}$ onboard aerated fish holding tank. Then, they were anesthetised by immersion in $10 \mathrm{l}$ of filtered sterile seawater containing $100 \mathrm{mg} \mathrm{l}^{-1}$ of tricaine methanesulfonate (MS222). Each acoustic tag was surgically implanted into the peritoneal cavity through a dorsoventral incision and sutured using non-absorbable sutures (Mersilk, 4-0, Ethicon), maximising sterile conditions. The entire surgical process took $<5$ min. The fish was then placed in the onboard tank to recover until normal behaviour was observed (i.e. the effects of the MS222 disappeared). The fish were subsequently released from the boat at the same position where they had been captured and visually monitored until they reached the soft bottom, avoid-

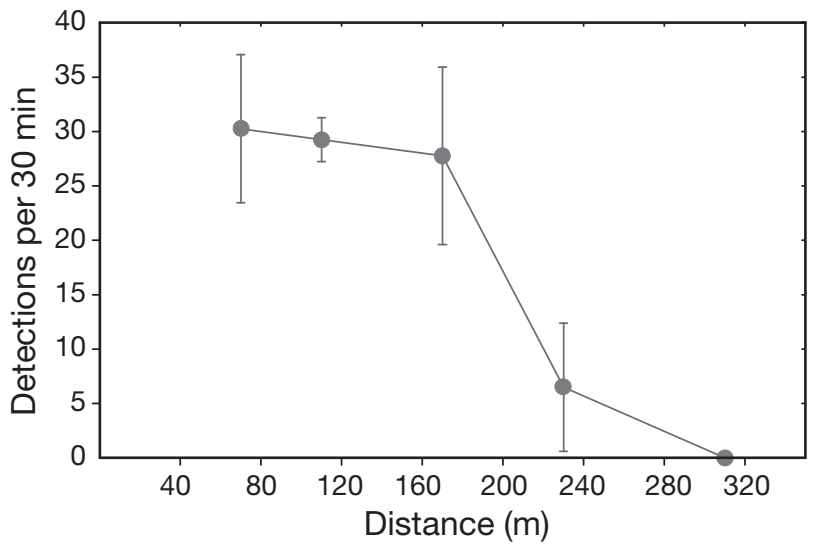

Fig. 2. Detection range test. Means $\pm 95 \% \mathrm{CI}$ of the detections per $30 \mathrm{~min}(\mathrm{n}=4)$ against the distance $(\mathrm{m})$ obtained in the test. Variation of the depth $(\mathrm{m})$ in the study area was $<10 \mathrm{~m}$, and the range tests were done at the average depth ( 23 to $24 \mathrm{~m}$ ). The test was carried out by mooring 5 different receivers (with the same configuration used in the tracking experiment) at different distances from an acoustic tag (the same used to tag individuals of Xyrichtys novacula). Results showed a strong decrease at $200 \mathrm{~m}$ and a maximum detection range of $300 \mathrm{~m}$ 
Table 1. Xyrichtys novacula. Characteristics of the implanted acoustic tags (frequency) and individuals of $X$. novacula tagged (total length, weight and sex). ID: identification number. Release: day when the fish was tagged and released. Detections: total count of the detections downloaded from the array. Receivers: number of receivers that detected a specific fish. $\mathrm{TP}_{i}$ : period between the release date and the last detection for fish $i_{i} \mathrm{DD}_{i}$ : total number of days detected; $\mathrm{RI}_{i}$ : residence index

\begin{tabular}{|c|c|c|c|c|c|c|c|c|c|c|}
\hline Fish ID & $\begin{array}{l}\text { Total length } \\
\text { (mm) }\end{array}$ & $\begin{array}{l}\text { Weight } \\
\text { (g) }\end{array}$ & Sex & $\begin{array}{l}\text { Frequency } \\
\quad(\mathrm{kHz})\end{array}$ & $\begin{array}{l}\text { Release } \\
(\mathrm{dd} / \mathrm{mm})\end{array}$ & Detections & Receivers & $\begin{array}{l}\mathrm{TP}_{i} \\
\text { (d) }\end{array}$ & $\begin{array}{l}\mathrm{DD}_{i} \\
\text { (d) }\end{array}$ & $\mathrm{RI}_{i}$ \\
\hline 1 & 190 & 75 & Male & 70 & $26 / 07$ & 1648 & 15 & 22 & 14 & 0.6 \\
\hline 2 & 187 & 72 & Male & 71 & $26 / 07$ & 37106 & 14 & 23 & 23 & 1 \\
\hline 3 & 202 & 85 & Male & 72 & $26 / 07$ & 4791 & 16 & 8 & 8 & 1 \\
\hline 4 & 209 & 93 & Male & 73 & $26 / 07$ & 50327 & 16 & 22 & 22 & 1 \\
\hline 5 & 189 & 74 & Male & 74 & $26 / 07$ & 22537 & 17 & 23 & 23 & 1 \\
\hline 6 & 159 & 51 & Female & 75 & $26 / 07$ & 15269 & 7 & 17 & 17 & 1 \\
\hline 7 & 185 & 70 & Male & 76 & $26 / 07$ & 30074 & 18 & 22 & 22 & 1 \\
\hline 8 & 158 & 50 & Female & 77 & $26 / 07$ & 67171 & 12 & 23 & 23 & 1 \\
\hline 9 & 158 & 54 & Female & 78 & $26 / 07$ & 13189 & 13 & 22 & 22 & 1 \\
\hline 10 & 153 & 54 & Female & 79 & $26 / 07$ & 25929 & 17 & 22 & 22 & 1 \\
\hline 11 & 159 & 53 & Female & 80 & $26 / 07$ & 60147 & 13 & 23 & 23 & 1 \\
\hline 13 & 192 & 75 & Male & 82 & $26 / 07$ & 69652 & 17 & 23 & 23 & 1 \\
\hline Control tag & - & - & - & 81 & $28 / 07$ & 103279 & 13 & 21 & 21 & 1 \\
\hline
\end{tabular}

ing post-release predation. As recommended by Payne et al. (2010), a control tag (the same model as that used for the fishes; Table 1) was moored in the receiver array during the tracking period to help rule out environmental effects on the detection patterns (Table 1). The position, depth (m), day and hour were recorded for each tagged fish prior to its release.

\section{Data analysis}

An MS Access database was used to store and manage all of the obtained detection data. Additionally, data from the US Naval Observatory (http://aa. usno.navy.mil/) were used to develop temporal categories of day and night based on local sunrise and sunset data. In terms of temporal patterns, the number of days on which a specific tagged fish (i) was detected $\left(\mathrm{DD}_{i}\right)$ was divided by the period between the release and the last detection date $\left(\mathrm{TP}_{i}\right)$ to calculate a residence index $\left(\mathrm{RI}_{i}\right)$ within the receiver array (March et al. 2010, Alós et al. 2011). The temporal pattern of detections was then examined by visually examining chronograms of the hourly detections of each individual and the hourly means plot of the detections.

A continuous wavelet transform (CWT) was then used to detect any periodicity in the detection pattern at different time scales. The mathematical robustness and predictive ability of CWT make it one of the most promising tools for use in multi-scale movement ecology, which couples the study of animal behaviour and environmental properties (Gaucherel 2011). The
CWT allows a time-series to be broken down into time-frequency space, providing an alternative to Fourier analysis or other time-frequency decomposition methods (Percival \& Walden 2000) to identify temporal patterns in movement data (Gaucherel 2011) or in data obtained from acoustic tracking experiments (March et al. 2010, Alós et al. 2011). The sowas library in R package (www.r-project.org/) was used to compute the 2-dimensional wavelet spectrum and to perform a point-wise test at a $95 \%$ significance level for each tagged fish and for the control tag (Maraun et al. 2007). Wavelet coefficient values were normalised such that the highest spectral power was equal to 1 (March et al. 2010).

The spatial analysis was based on the NadarayaWatson kernel estimator (sm library in $\mathrm{R}_{i}$ Bowman \& Azzalini 1997), which was used to calculate the centre of activity positions (COAs) for the tracked fish $i$ in 60 min time steps. Thus, estimation of the $\mathrm{XY}_{i}$ positions for Fish $i$ was based on the positions of the receivers that detected the fish during a specific time-step period and weighted by the number of detections (Simpfendorfer et al. 2002). Then, 2 measures of the home range (HR) were estimated for each fish: (1) the minimum convex polygon based on $100 \%$ of the obtained positions $(100 \%$ $\mathrm{MCP}_{i}$ ) and (2) the cumulative and daily HR (based on the diel phases) as the bivariate fixed-kernel utilisation distributions (95 and $50 \% \mathrm{KUD}_{i}$ ). These HR estimates were based on the COAs estimated for each fish over a grid with a $50 \times 50 \mathrm{~m}$ resolution using the adehabitat library in the $\mathrm{R}$ package (Calenge 2006). 
KUDs are more robust than MCP to identify outlier COAs because they include a kernel bandwidth (KB) that allows consideration of the error estimations for the COAs (March et al. 2010, Alós et al. 2011). In contrast to previous studies that used a $\mathrm{KB}$ equal to the detection range (e.g. March et al. 2010), we obtained a direct measure of the positioning error based on the estimated COAs and the true position of the control tag. KB was considered to be equal to the mean of the positioning error of our control tag (see 'Results'). Thus, the COAs of the control tag were estimated and then compared with the known true position to directly estimate position error ( 90 m, see 'Results'). Using this $\mathrm{KB}$ value, the obtained KUD estimates were more accurate but remained conservative due to the error in positioning obtained through acoustic telemetry.

The HR area is expected to increase over time and to eventually arrive at an asymptotic value when a fish has explored most of its true home range (Börger et al. 2008). Thus, temporal changes in the daily cumulative HR size were examined visually using HR curves. We assumed that the asymptotic HR (based on the 95\% KUD) was reached when the percentage of difference between 2 consecutive days for the accumulated HR was $<5 \%$ (Rechisky \& Wetherbee 2003). Changes in HR size related to diel behaviour were also investigated using the index of reuse (IOR; Rechisky \& Wetherbee 2003). The daily $\mathrm{IOR}_{i}$ was estimated for each fish $i$ as $\operatorname{IOR}_{i}=\left[\operatorname{OV}_{i}\left(A_{1}, A_{2}\right)\right] \div$ $\left(A_{1}+A_{2}\right)$, where $A_{1}$ and $A_{2}$ are the activity spaces, and $\mathrm{OV}_{i}\left(A_{1}, A_{2}\right)$ is the area of overlap between the 2 activity spaces (i.e. the daily accumulated $50 \%$ or $95 \%$ KUD areas for each diel phase; (Rechisky \& Wetherbee 2003). Values of $\mathrm{IOR}_{i}$ close to 1 indicate a large overlap between the activity spaces and imply high site fidelity and an absence of diel differences in spatial utilisation. In contrast, values of $\mathrm{IOR}_{i}$ close to 0 indicate that the diel activity spaces are different, suggesting the occurrence of some type of daily migration (e.g. Hitt et al. 2011). Finally, the linearity index $\left(\mathrm{LI}_{i}\right)$ was estimated as an indicator of the direction of the fishes' movements (random vs. directional movement) and site fidelity. The index was calculated according to Alós et al. (2011).

\section{Modelling spatio-temporal patterns}

Significant temporal and spatial patterns were checked via generalised linear mixed models (GLMM; Zuur et al. 2009). The total daily detections pooled per diel phase (standardised based on the dif- ferent duration of each phase) and the daily HR utilisation (based on the 95\% KUD) structured by diel phases (day and night) for each fish were considered as dependent variables $(y)$ in 2 different GLMM. In both cases, the diel phase (day vs. night) and sex as well as their interaction effects were considered as independent variables and treated as fixed factors.

Because the data were composed of repeated measures within individuals and within different tracking days, we considered the fish identity (ID) as a random factor and grouped the data based on the tracking date. The 2 different models (spatial and temporal) were fitted using the glmm.admb function of the glmm $A D M B$ library in the R package. In both cases, the data did not exhibit a Gaussian distribution (even after efforts at transformation). However, using a Poisson distribution without zero inflation, the residual distribution was normal (family = Poisson in the glmmADMB library). The normality of the residuals and model performance were examined by visual inspection of the residual distributions, plotting the residuals against the fitted values and using quantile-quantile $(\mathrm{QQ})$ plots.

\section{RESULTS}

\section{General results}

A total of 501119 detections (with a mean and standard deviation [SD] of $38548 \pm 29941.2$ detections per fish) were obtained during the study period (Table 1). The maximum number of detections was for the control tag (103279 detections; Table 1). Tagged fish were detected by 15 receivers on average $(\mathrm{SD}=3.1$ receivers), whereas the control tag was detected by 13 different receivers (Table 1). In terms of the $\mathrm{TP}_{i}$, the fish were tracked for a period of $3 \mathrm{wk}$ (mean $\pm \mathrm{SD}=21 \pm 4.36 \mathrm{~d}$ ), and the control tag was detected for $23 \mathrm{~d}$, notably exceeding the expected life span $(12 \mathrm{~d})$ of the tags provided by Sonotronics (Table 1).

The $\mathrm{DD}_{i}$ were equal to the $\mathrm{TP}_{i}$ in almost all cases, obtaining the maximum values for the residency index $\left(\mathrm{LI}_{i}\right.$; Table 1). Fish 1 and 3 had the lowest numbers of detections, and the temporal chronograms for these fish suggested possible mortality or tag loss, e.g. if the sutures did not hold (Table 1). Similarly, after $11 \mathrm{~d}$ of tracking, Fish 8 either died or lost its tag, exhibiting a nearly constant detection pattern (see 'Temporal patterns' and Fig. 3). Thus, Fish 1 and 3 and the period after 6 August for Fish 8 were not considered in the data analysis. 


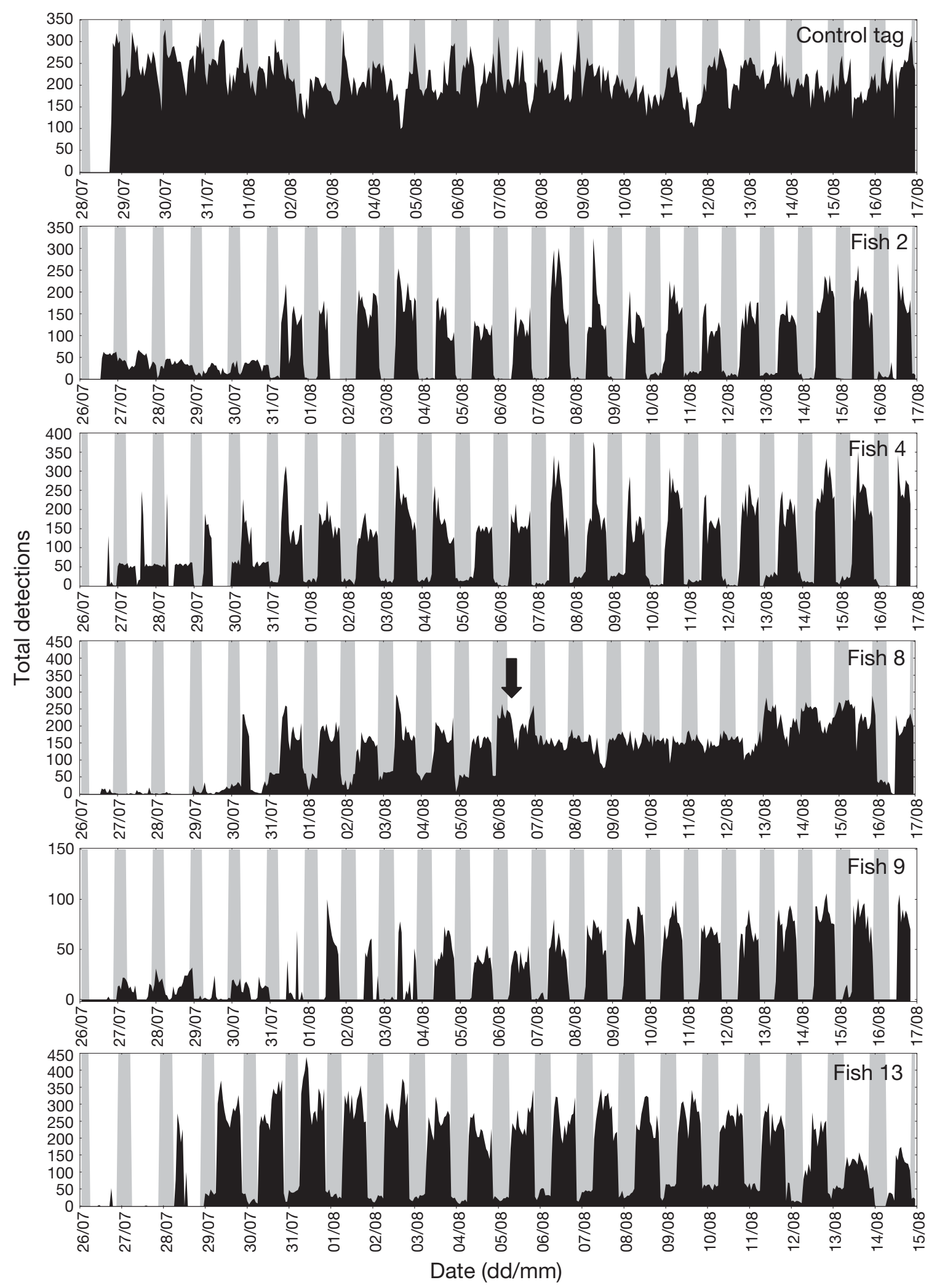

Fig. 3. Xyrichtys novacula. Hourly detections over the tracking period for the control tag and tagged Fish 2, 4, 8, 9 and 13. Vertical stripes indicate day (white) or night (grey) related to the local sunrise and sunset time. Note the higher number of detections during the day and the loss of a diel pattern after $12 \mathrm{~d}$ of tracking in Fish 8 . No temporal pattern can be recognized in the control tag plot 


\section{Temporal patterns}

Chronograms of hourly detections showed a clear temporal pattern (diel based) characterised by a strong decrease in the number of detections during the night (Fig. 3). During the first several days after the fish were tagged, the detection pattern was irregular, characterised by few detections, suggesting abnormal behaviour during a short period after capture and implantation (Fig. 3). These patterns were not observed in the chronogram of the control tag, indicating that this was not an environmental effect (Fig. 3).

The means plot also showed a diel pattern of greater numbers and variability of detections in daylight hours (Fig. 4), which was not seen with the control tag. The analysis performed using the CWT clearly confirmed this diel behaviour, with a significant periodicity (marked by the 95\% significance level) detected at the $24 \mathrm{~h}$ scale in most cases (see examples for 4 different fish in Fig. 5). The abnormal behaviour during a short period after capture and implantation was also confirmed by the CWTs (Fig. 5). The CWT performed for the control tag did not show any temporal periodicity, and no other significant temporal behaviour was detected at any temporal scale for the tagged fishes (Fig. 5).

These temporal behaviours were significant, with a significant increase in detections occurring during daylight hours ( $\mathrm{p}<0.001$; Table 2 ), and no significant difference between sexes was observed $(p=0.37$; Table 2). However, the interaction effects between the diel phase and sex were significant, with males exhibiting lower mean detection rates during the night $(\mathrm{p}<0.001$; Table 2$)$.

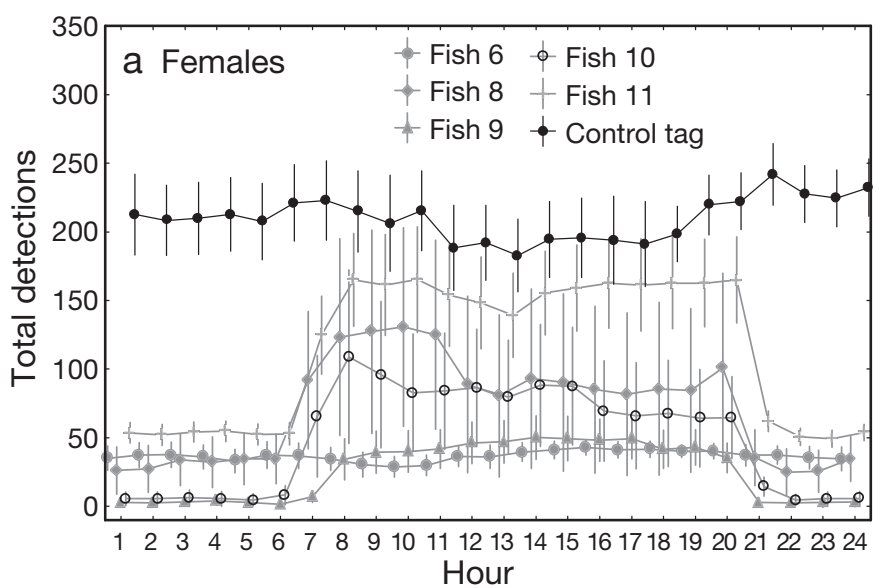

\section{Spatial patterns}

A total of $456 \pm 57.6$ (mean $\pm \mathrm{SD}$ ) COAs were estimated for the tagged fish (Table 3). For the control tag, a total of 471 COAs were estimated and compared with the true TAG position (Table 3 ). The COA estimation error varied by $87.8 \pm 38.4 \mathrm{~m}$ (mean \pm SD) over time, without any temporal pattern (Fig. 6). The positioning error estimated for the latitude and longitude is plotted in Fig. 6. The mean minimum convex polygon (MCP) estimated for all of the COAs for the tagged fish was $0.15 \pm 0.12 \mathrm{~km}^{2}$ (Table 3 )

The mean accumulated bivariate fixed $\mathrm{KUD}_{i}$ estimated for the tagged fish were $0.32 \pm 0.13 \mathrm{~km}^{2}$ and $0.07 \pm 0.02 \mathrm{~km}^{2}$ for the $95 \%$ and $50 \%$ KUDs, respectively (Table 3 ). The variation in the daily cumulative $95 \%$ KUDs is represented in Fig. 7. The home range area (based on the 95\% KUD) for all fishes reached an asymptote after $7.6 \pm 4 \mathrm{~d}$ (mean $\pm \mathrm{SD}$; Fig. 7, Table 3). Fig. 8 shows the spatial plot with the MCPs and $95 \%$ and $50 \%$ KUDs of Fishes 2, 4, 5, $6,7,9,10,11$ and 13 for the purpose of visualising the general patterns of habitat utilisation. Spatial utilisation was similar for both night and day, with mean \pm SD for the $95 \%$ KUDs of $0.31 \pm 0.13 \mathrm{~km}^{2}$ for day and $0.29 \pm 0.11 \mathrm{~km}^{2}$ for night (Table 4). In the case of the $50 \%$ KUDs, these values were $0.06 \pm$ $0.02 \mathrm{~km}^{2}$ and $0.05 \pm 0.01 \mathrm{~km}^{2}$, respectively (Table 3 ). Spatial modelling did not show any significant effect for the diel phase, sex or their interaction (Table 2).

The values (mean $\pm \mathrm{SD}$ ) for the $\mathrm{IOR}_{i}$ ranged from $0.48 \pm 0.1$ to $0.96 \pm 0.06$ and from $0.18 \pm 0.09$ to $0.91 \pm$ 0.12 for the $95 \%$ and $50 \%$ KUDs, respectively, and in most cases, were $>0.5$, suggesting a high degree of overlap between day and night activity spaces

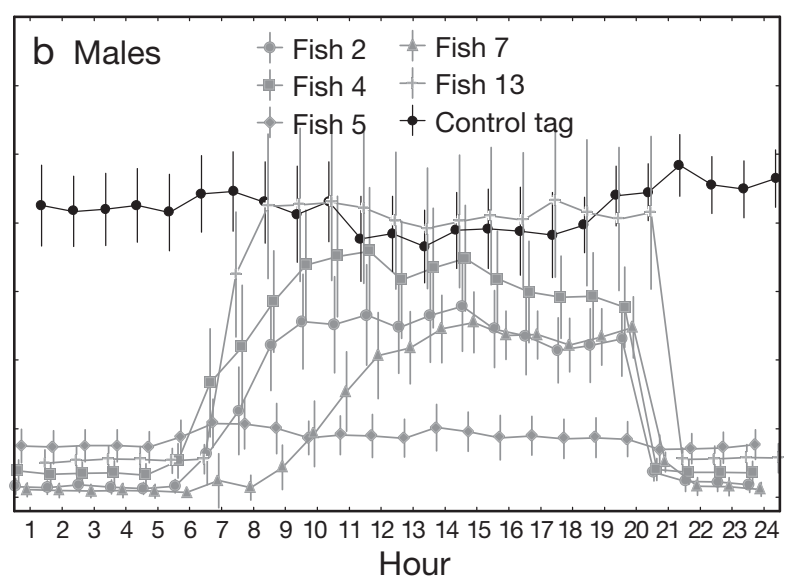

Fig. 4. Xyrichtys novacula. Detections per hour (mean \pm CI) during a daily period. Control tag and (a) females and (b) males 

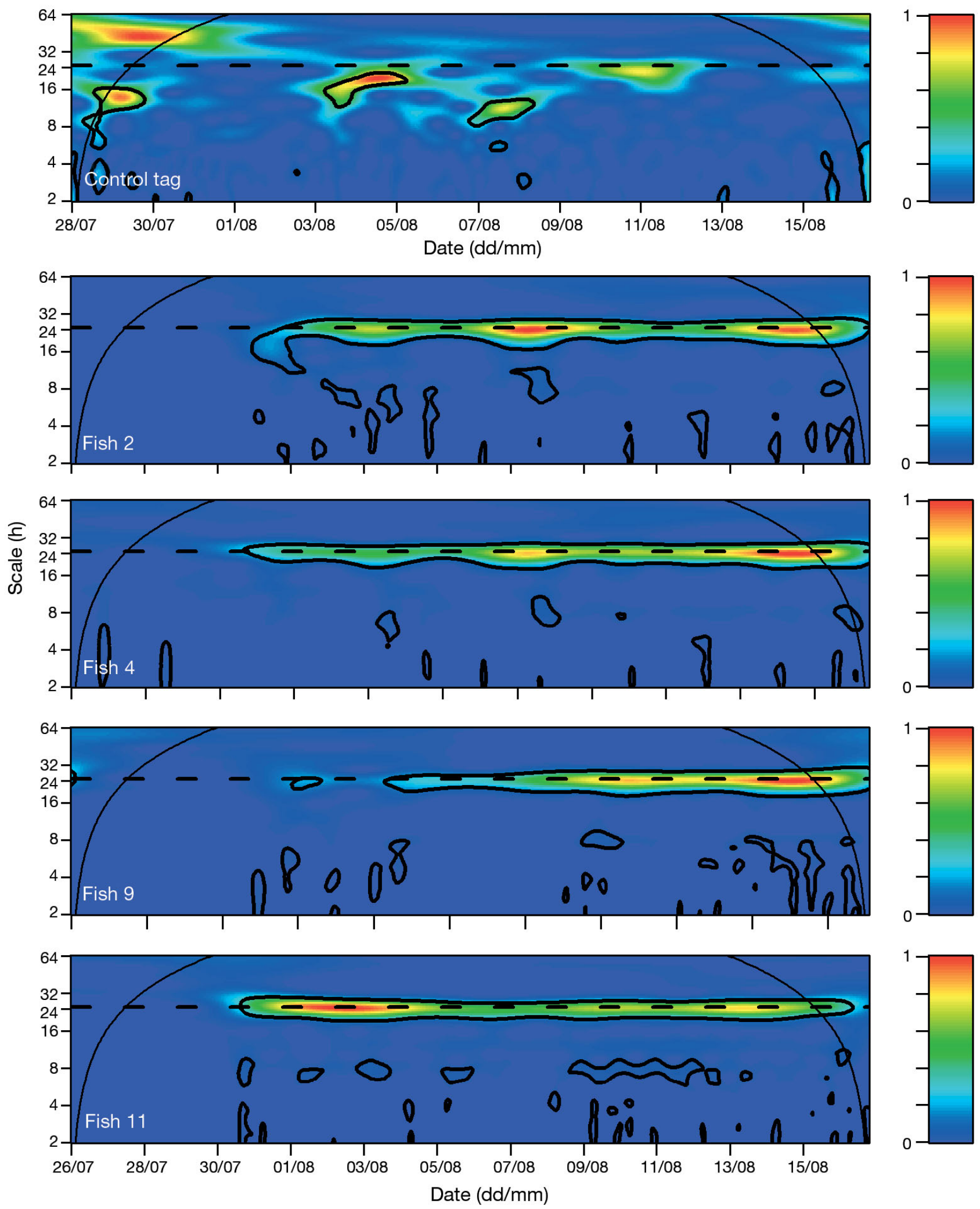

Fig. 5. Xyrichtys novacula. Wavelet sample spectra fitted for the control tag and Fish 2, 4, 9 and 11. Continuous thin lines represent the cone of influence (COI), and values outside the COI should not be interpreted due to edge effects. Thick contours represent the $95 \%$ confidence level, and significant periodicities were detected in all cases on a $24 \mathrm{~h}$ scale (indicated as a horizontal dashed line). No periodicity in the detection pattern was detected in the control tag 
Table 2. Xyrichtys novacula. Estimate, standard error, z-values and p-values obtained in generalised linear mixed models fitted to test (a) temporal (mean detections per diel phase) and (b) spatial (mean home range per diel phase) patterns. In both cases, the independent variables (fixed factors) were the diel phase (day vs. night), sex (male vs. female) and their interaction. ${ }^{* * *}$ very highly significant

\begin{tabular}{|c|c|c|c|}
\hline & Estimate $\pm \mathrm{SE}$ & $z$ & $\operatorname{Pr}(>|t|)$ \\
\hline \multicolumn{4}{|c|}{ a) Temporal patterns (log-daily detections) } \\
\hline (Intercept) & $6.61 \pm 0.48$ & 13.65 & $<0.001^{* * *}$ \\
\hline Diel phase (night) & $-2.03 \pm 0.05$ & -37.15 & $<0.001^{* * *}$ \\
\hline Sex (male) & $0.29 \pm 0.32$ & 0.90 & 0.37 \\
\hline Diel phase (night) $\times$ Sex (male) & $-0.26 \pm 0.06$ & -4.58 & $<0.001^{* * *}$ \\
\hline \multicolumn{4}{|c|}{ b) Spatial patterns (log-spatial utilisation) } \\
\hline (Intercept) & $-1.77 \pm 0.25$ & -7.08 & $<0.001^{* * *}$ \\
\hline Diel phase (night) & $-0.05 \pm 0.36$ & -0.14 & 0.89 \\
\hline Sex (male) & $0.07 \pm 0.33$ & 0.21 & 0.84 \\
\hline Diel phase (night) $\times$ Sex (male) & $0.00 \pm 0.48$ & 0.01 & 0.99 \\
\hline
\end{tabular}

\section{DISCUSSION}

The pearly razorfish Xyrichtys novacula is a small labrid that is widely targeted by the professional and recreational fisheries in the Mediterranean. Due to this intense exploitation, some of its populations have been overexploited, and various spatio-temporal management strategies have been adopted for this species. In the present study, we provide the first attempt to determine habitat use by this species by employing acoustic telemetry in a temperate MPA. This species exhibited clear diel behaviour affecting their vulnerability to fishing, as they bury themselves in the sand at night. In terms of spatial patterns, $X$. novacula individuals exhibited small HR of $<0.5 \mathrm{~km}^{2}$ and high site fidelity, indicating that small MPAs represent a promising management tool for this species. In this first acoustic telemetry study of $X$. novacula, we
(Table 4). Finally, all of the values of the $\mathrm{LI}_{i}$ were close to 0 , with a mean $\pm \mathrm{SD}$ of $0.04 \pm 0.02$, showing a high degree of site fidelity, thus rejecting the hypothesis of nomadic movement in favour of the hypothesis of random movements (Table 4).

Table 3. Xyrichtys novacula. Number of centres of activity positions (COA), minimum convex polygons based on $100 \%$ of the positions (100\% MCPs), the asymptote value (i.e. day on which the accumulated home range changed $<5 \%$ ) and the accumulated and diel-based bivariate normal fixed kernel utilisation distributions (95 and $50 \%$ KUD) in $\mathrm{km}^{2}$ estimates for each tagged fish $i$

\begin{tabular}{|c|c|c|c|c|c|c|c|c|c|c|}
\hline \multirow{2}{*}{ Fish ID } & \multirow{2}{*}{ Sex } & \multirow{2}{*}{$\mathrm{COA}_{i}$} & \multirow{2}{*}{$\mathrm{MCP}_{i}$} & \multirow{2}{*}{$\begin{array}{l}\text { Asymptote } \\
\text { (d) }\end{array}$} & \multicolumn{3}{|c|}{$-\mathrm{KUD}_{i} 95 \%$} & \multicolumn{3}{|c|}{$\longrightarrow \mathrm{KUD}_{i} 50 \%$} \\
\hline & & & & & Accumulated & Day & Night & Accumulated & Day & Night \\
\hline 2 & Male & 489 & 0.11 & 7 & 0.36 & 0.34 & 0.32 & 0.08 & 0.07 & 0.06 \\
\hline 4 & Male & 493 & 0.17 & 7 & 0.35 & 0.33 & 0.33 & 0.09 & 0.08 & 0.05 \\
\hline 5 & Male & 507 & 0.28 & 10 & 0.45 & 0.47 & 0.41 & 0.07 & 0.07 & 0.07 \\
\hline 6 & Female & 391 & 0.01 & 1 & 0.16 & 0.16 & 0.15 & 0.04 & 0.04 & 0.04 \\
\hline 7 & Male & 435 & 0.36 & 5 & 0.48 & 0.47 & 0.45 & 0.07 & 0.06 & 0.07 \\
\hline 8 & Female & 500 & 0.04 & 4 & 0.21 & 0.21 & 0.20 & 0.04 & 0.04 & 0.04 \\
\hline 9 & Female & 359 & 0.15 & 9 & 0.32 & 0.31 & 0.33 & 0.07 & 0.06 & 0.08 \\
\hline 10 & Female & 392 & 0.25 & 13 & 0.51 & 0.51 & 0.43 & 0.11 & 0.11 & 0.07 \\
\hline 11 & Female & 523 & 0.02 & 14 & 0.17 & 0.17 & 0.15 & 0.04 & 0.04 & 0.04 \\
\hline 13 & Male & 471 & 0.09 & 6 & 0.21 & 0.20 & 0.17 & 0.05 & 0.05 & 0.04 \\
\hline
\end{tabular}

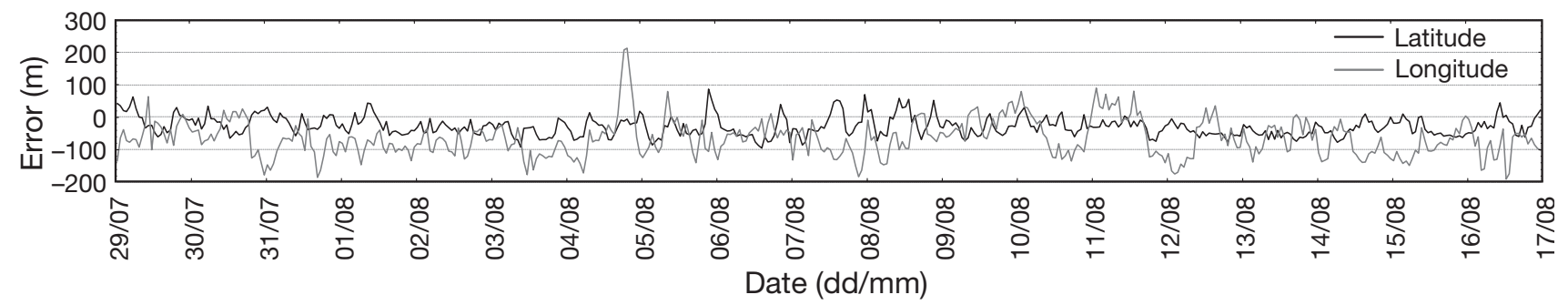

Fig. 6. Positioning error $(\mathrm{m})$ of the hourly estimated centre of activity positions of the control tag. Latitude and longitude errors are individually represented 

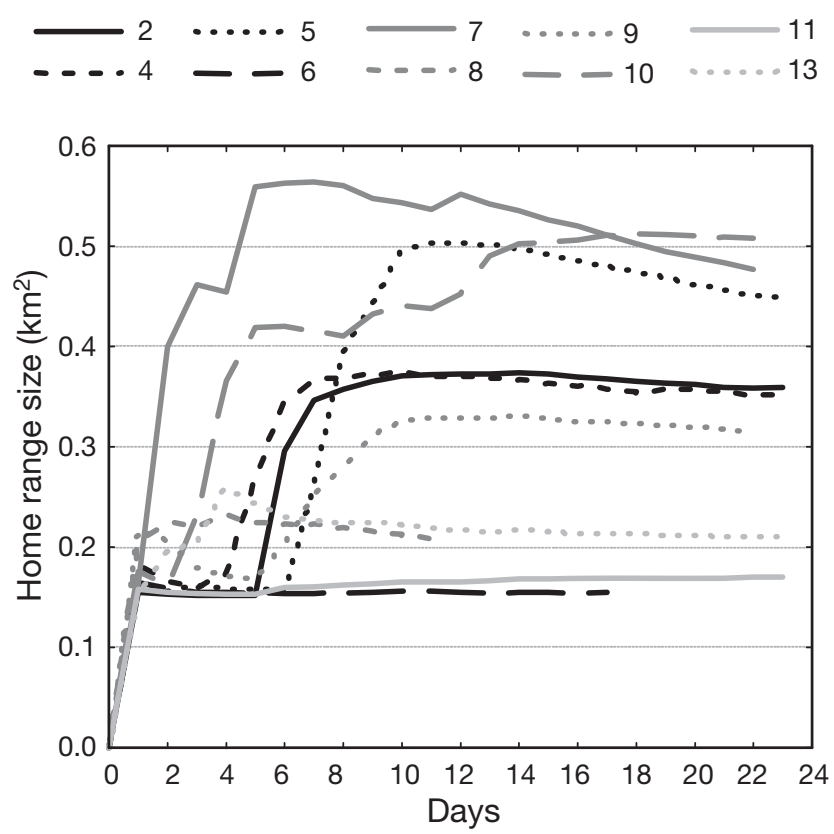

Fig. 7. Xyrichtys novacula. Daily cumulative home range estimates $\left(\mathrm{km}^{2}\right.$; based on $95 \%$ kernel utilisation distributions) of the tagged fish nos. 2, 4 to 11 , and 13

were able to incorporate emerging techniques to improve the array's accuracy and to demonstrate the effectiveness of miniaturised acoustic tags for studying a small-bodied species.

Two main methodological improvements adopted here should be mentioned because they can be generalised to any type of acoustic telemetry experiment. (1) The applicability of control tags and their ability to track changes in detection due to environmental or biological causes has recently been noted (see details in Payne et al. 2010). Here, the use of a control tag allowed us not only to discard any environmental pattern in the detection pattern (the detection pattern was time-independent) but also to confirm that the decrease in nighttime detections was biological and most likely due to the 'burying' behaviour characteristic of this species (Katsanevakis 2005). (2) It is generally assumed that the behaviour of tagged fish is normal if proper surgical procedures and tag choices have been applied. However, in this study, several days post-release passed before the fish returned to normal behaviour (Fig. 3). The tagged fish in our study were less mobile and may have buried themselves during the first 3 to $4 \mathrm{~d}$ after tag implantation. Normal behaviour (mainly characterised by the diel pattern) subsequently returned for all of the tagged fish. Therefore, this result should be considered in further experiments in this species.
Significant changes in diel behaviour have previously been reported for marine coastal species in the Mediterranean (Jadot et al. 2002, March et al. 2010, Alós et al. 2011). However, the ability to infer diel behaviour from detection patterns is a controversial issue, and different behaviours can generate the same diel detection pattern, including daily migrations (e.g. Hitt et al. 2011), hiding behaviour during the night (e.g. March et al. 2010) or fluctuations in environmental conditions (Payne et al. 2010). In some cases, the detection pattern changes because fish remain hidden during the night, and the decrease in detection is purely motivated by physical factors. This is the case for many species associated with a particular structure, such as many reef fish species (e.g. Topping et al. 2005) and even some species inhabiting seagrass meadows (March et al. 2010, Alós et al. 2011).

This also appears to be the case for Xyrichtys novacula. It is well known that this species exhibits feeding (Cardinale et al. 1997), mating (experiment performed in the spawning season; Marconato et al. 1995, Cardinale et al. 1998) and social behaviours (Marconato et al. 1995) during the day. It has also been previously reported that this fish may bury itself in the sand during the night to rest (Katsanevakis 2005). This diel behaviour pattern was supported by the detection pattern obtained in the present study, with significantly more detections during the day than the night. Moreover, use of the control tag (a tag set just $1 \mathrm{~m}$ from the bottom) indicated that it was fish behaviour rather than environmental fluctuations that caused the decrease in nighttime detections (Payne et al. 2010).

Wavelet analysis was helpful for analysing the periodicities in the tag detections and, thus, the diel behaviour of Xyrichtys novacula. Wavelet analysis has been used successfully to determine periodicities in other Mediterranean fishes and at other time scales (March et al. 2010, Alós et al. 2011), confirming the usefulness of this tool for detecting regime shifts in fish movement. The diel behaviour exhibited by $X$. novacula was independent of sex and, thus, not due to a factor affecting general detections, such as the thicker body wall in males (because males are bigger than females). However, the interaction between diel phase and sex was significant, with males detected less during nighttime. Two possible behavioural explanations for why the probability of detecting males is lower compared to females during the nighttime are that (1) males may bury themselves more completely or deeply than females and that (2) males may remain buried for a longer time period than females. 

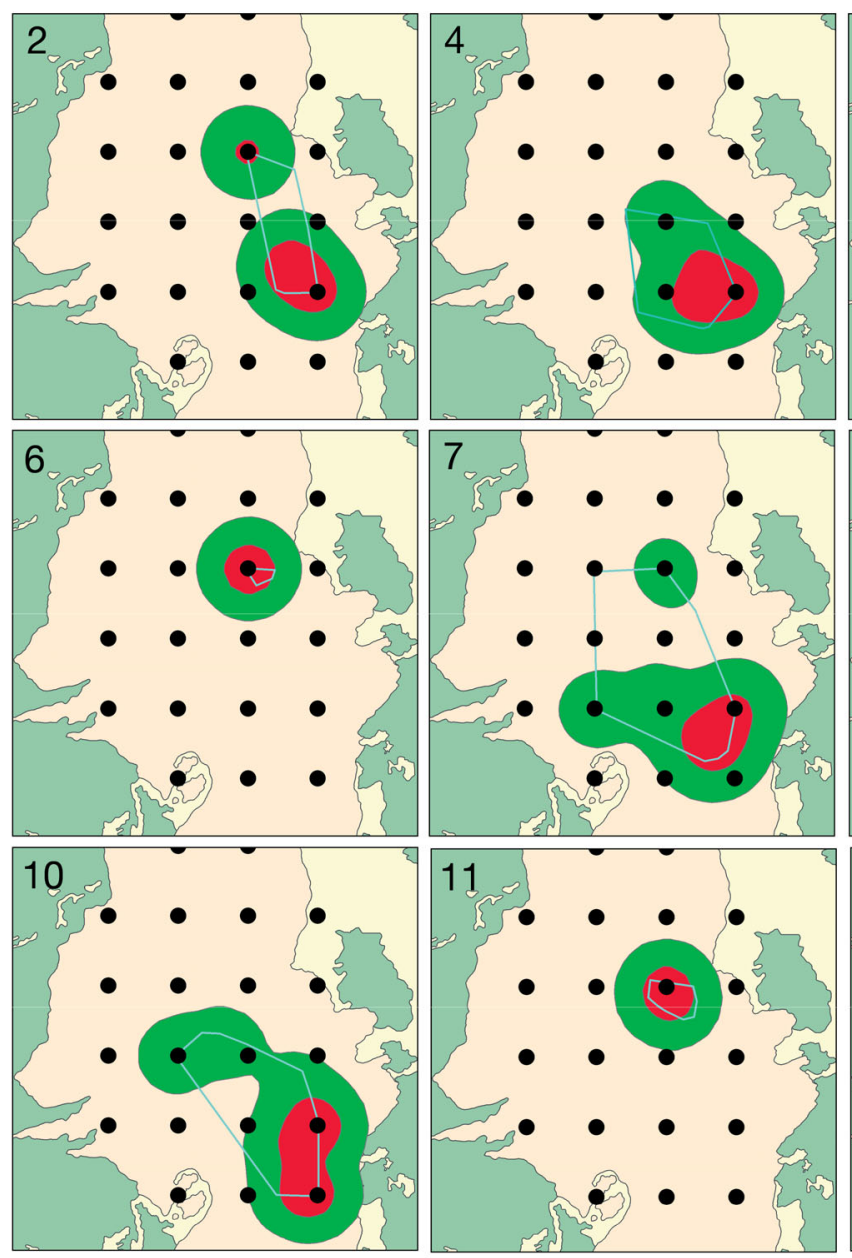

The results of the present study further support previous research indicating the preference of this species for soft bottom habitats. In fact, it has previously been reported that there is a relationship between the abundance of Xyrichtys novacula and micro-habitat

Table 4. Xyrichtys novacula. Individual mean \pm SD of the index of reuse $\left(\mathrm{IOR}_{i}\right)$ based on the 95 and $50 \%$ kernel utilization distributions [KUD] and the linearity index $\left(\mathrm{LI}_{i}\right)$

\begin{tabular}{|lccc|}
\hline $\begin{array}{l}\text { Fish } \\
\text { no. }\end{array}$ & $\begin{array}{c}\mathrm{IOR}_{i}(95 \% \mathrm{KUD}) \\
\text { Mean } \pm \mathrm{SD}\end{array}$ & $\begin{array}{c}\mathrm{IOR}_{i}(50 \% \mathrm{KUD}) \\
\text { Mean } \pm \mathrm{SD}\end{array}$ & $\mathrm{LI}_{i}$ \\
\hline 2 & $0.62 \pm 0.21$ & $0.36 \pm 0.34$ & 0.03 \\
4 & $0.50 \pm 0.19$ & $0.19 \pm 0.29$ & 0.04 \\
5 & $0.87 \pm 0.20$ & $0.82 \pm 0.23$ & 0.07 \\
6 & $0.96 \pm 0.06$ & $0.91 \pm 0.12$ & 0.06 \\
7 & $0.61 \pm 0.17$ & $0.32 \pm 0.28$ & 0.04 \\
8 & $0.77 \pm 0.14$ & $0.59 \pm 0.23$ & 0.01 \\
9 & $0.67 \pm 0.20$ & $0.48 \pm 0.28$ & 0.04 \\
10 & $0.67 \pm 0.20$ & $0.47 \pm 0.32$ & 0.08 \\
11 & $0.74 \pm 0.13$ & $0.54 \pm 0.22$ & 0.01 \\
13 & $0.48 \pm 0.10$ & $0.18 \pm 0.09$ & 0.01 \\
\hline
\end{tabular}

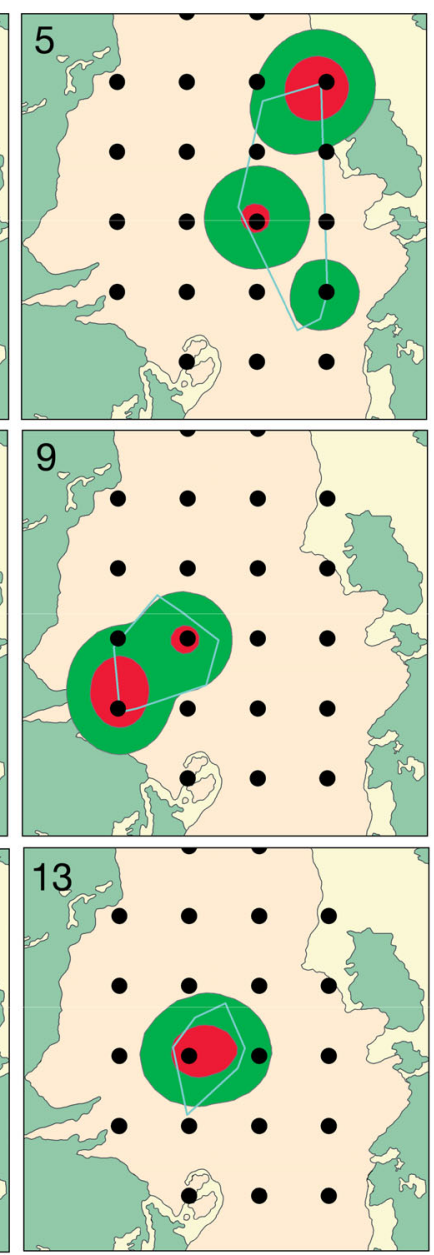

Habitat

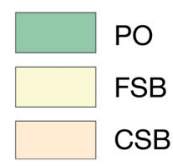

$\begin{array}{lll}0 & 0.3 & 0.6 \mathrm{~km}\end{array}$

Fig. 8. Xyrichtys novacula. Estimated space utilisation of the tagged fish $(2,4,5,6$, $7,9,10,11$, and 13) determined from the minimum convex polygon based on $100 \%$ of the obtained positions $\left(\mathrm{MCP}_{i}\right)$ and the bivariate fixed-kernel utilisation distributions, $50 \%(\bullet)$ and $95 \%(0)$ kernel utilisation distributions $\left(\mathrm{KUD}_{i}\right)$. $\bullet$ : Fixed acoustic receivers. Habitat types were categorised as Posidonia oceanica seagrasses (PO), fine sand bottoms (FSB) and coarse sand bottoms (CSB)

characteristics in terms of grain size, with $X$. novacula preferring bottom habitats of a medium grain diameter (Katsanevakis 2005) and seagrass vegetation of Cymodocea nodosa (Tuya et al. 2005). In this preferred habitat, individuals feed mostly on benthic crustaceans and molluscs within the fine and wellsorted sand assemblages (Cardinale et al. 1997). Unfortunately, this kind of micro-habitat characterisation is not available for our study area as in the previous work by Katsanevakis (2005), and only 2 main habitats were available (fine and coarse sand bottoms). However, the abundance of $X$. novacula appeared to be higher in the receiver array (mainly dominated by coarse sand bottoms with grain size from 0.5 to $1 \mathrm{~mm}$ ) than in the northern and northeastern areas of the study site, where fine sand bottom (grain size from 0.125 to $0.250 \mathrm{~mm}$; see Fig. 1) is the main habitat (J. Alós pers. comm.). Thus, this type of bottom habitat would appear to represent an important consideration for future MPAs for this species.

The present study highlighted the importance of acoustic telemetry for the validation of visual obser- 
vations, which are typically carried out over limited time periods and spaces. For example, although previous observations performed for periods of several hours suggested that this species was sedentary, with a habitat utilisation area of 400 to $800 \mathrm{~m}^{2}$ (Marconato et al. 1995), our method allowed us to track individuals for up to $3 \mathrm{wk}$ in most cases. In all cases, the tracking period was sufficiently long that habitat utilisation reached an asymptote, meaning that additional tracking time was not necessary to obtain the HR areas for both males and females (the average time to reach the asymptote value was $>1 \mathrm{wk}$ ).

Our results indicate that this species uses a small HR. Numerous hermaphrodites in Mediterranean coastal areas exhibit relatively small HR areas (e.g. Palmer et al. 2011). In most cases, these results regarding small habitat utilisation areas are in accord with species with complex social structures, often hermaphroditic, similar to Xyrichtys novacula. Previous data on the mating behaviour of this species indicated that their behaviour is haremic, and males patrol and defend females from other males (Marconato et al. 1995). As a consequence, relatively small habitat usage areas were expected for this species during the spawning season.

Although a clear diel pattern was observed in terms of the number of detections, the HR sizes were similar for day versus night. Therefore, although the fish remained buried during the night, they did not rest in the same place each night. Many marine fishes perform daily migrations (using different spaces on a daily basis) between foraging and resting areas (see the review by Krumme 2009 and some specific examples in Hitt et al. 2011). In fact, some Mediterranean species inhabiting Posidonia oceanica seagrasses perform daily migrations, using different areas for foraging versus resting (Jadot et al. 2002). However, other small species, such as species of the genus Serranus, that show increased activity during the day (hiding in meadows or rocks to prevent predation during the night) do not show a change in the cumulative size of their HR on a diel basis (March et al. 2010, Alós et al. 2011). This type of behaviour, where there is no site fidelity with respect to nighttime resting sites, appears to also be the case for Xyrichtys novacula. This trend was confirmed by the high degree of overlap between the day and night activity spaces used on a daily basis, rejecting the hypothesis of a specific site for resting.

There were also no sex-related differences in HR sizes. It has been observed that in some species of protogynous hermaphrodites, the larger individuals (males) exhibit smaller HR areas than the smaller (fe- male) individuals (e.g. Epinephelus lativa; KaundaArara \& Rose 2004). In the specific case of Xyrichtys novacula, previous short-term SCUBA observations of mating behaviour suggested that females occupy small areas, while males patrol and defend larger areas, usually encompassing 4 to 6 areas occupied by females (Marconato et al. 1995). Based on the results obtained here, the HR area used by females and males is not different, thus rejecting the hypothesis that males use larger areas, at least over the studied time scale ( 3 wk). Finally, the small spatial usage indicating a sedentary life style was confirmed by the low values of the LI. LI values close to 0 suggest that the movements of $X$. novacula are more related to random movements within the HR than directed movement, characterising this species as sedentary in general, with a limited adult dispersal capability and higher activity during the day than at night.

The results obtained here have direct implications for conservation and can be directly linked to the management of this species. (1) The overall results showed that Xyrichtys novacula uses small HR areas and exhibits high site fidelity with respect to these areas, with most activity occurring during the day. This finding implies that catchability will be strongly affected by local fishing pressure and the diel phase (day or night fishing activity). The high site fidelity observed makes this species a good coastal bioindicator of anthropogenic activity, such as fishing. (2) This species appears to have a strong affinity for a specific kind of habitat. The existing reports regarding habitat preferences of this species (Katsanevakis 2005, Tuya et al. 2005) and the results obtained here enhance the relevance of often unappreciated soft bottoms in the context of the protection of essential habitat for this species.

(3) A consequence of the sedentary pattern and small HR observed for Xyrichtys novacula is that relatively small protected areas could effectively protect this species during its spawning season. Similarly, relatively small MPAs could also reduce fishing mortality for fish located within the protected area. Consequently, greater numbers of older, larger individuals could be maintained inside the protected area, thereby producing a considerable increase in the reproductive potential of the population (due to the higher fecundity of older and larger fish). Thus, this pool of high-fecundity fish could be the key to maintaining sustainable population levels and preserving the naturally occurring genetic structure in the surrounding exploited areas through the movement of eggs and larvae (because spawning is pelagic; Marconato et al. 1995). Moreover, if the pop- 
ulation is allowed to increase in biomass, more adult individuals are likely to be observed closer to the boundary of the MPA and are expected to encounter fishing mortality beyond the protected area (Kramer \& Chapman 1999). All of this information should be useful for managers in designing MPAs, especially because the use of relatively small MPAs in the Mediterranean has increased recently (Francour et al. 2001). Finally, Katsanevakis (2005) reported that the habitat of $X$. novacula does not change outside the reproductive season, but different aspects of the behaviour of this species remain controversial (i.e. burying behaviour outside the reproductive season). Thus, further research should be performed in this vein, exploring all of the spatio-temporal patterns observed in the present study during the non-reproductive season. Then, all of these positive factors could be used to guide the exploitation of stocks of $X$. novacula in a direction favouring the sustainable development of this fishery.

Acknowledgements. We thank the people from the Direcció General de Pesca (Govern de les Illes Balears) and the researchers who helped with the experimental fishing and logistic procedures, especially A. Beltrán, S. Pérez, L. Buttay and C. Casas. The habitat map was obtained from the LIFE Posidonia program (Govern de les Illes Balears). We especially thank M. Palmer, B. Morales-Nin and D. March for their contribution to the experimental design and data analysis. This study was partially financed by the research project CONFLICT (CGL2008-00958), funded by the Spanish Ministry of Science and Innovation, and the research project ARTEVIGO (09MMA022402PR). J.A. was supported by an FPI fellowship (MICINN).

\section{LITERATURE CITED}

Alós J (2008) Influence of anatomical hooking depth, capture depth, and venting on mortality of painted comber (Serranus scriba) released by recreational anglers. ICES J Mar Sci 65:1620-1625

> Alós J, Palmer M, Grau AM, Deudero S (2008) Effects of hook size and barbless hooks on hooking injury, catch per unit effort, and fish size in a mixed-species recreational fishery in the western Mediterranean Sea. ICES J Mar Sci 65:899-905

> Alós J, Arlinghaus R, Palmer M, March D, Álvarez I (2009) The influence of type of natural bait on fish catches and hooking location in a mixed-species marine recreational fishery, with implications for management. Fish Res 97: 270-277

> Alós J, March D, Palmer M, Grau A, Morales-Nin B (2011) Spatial and temporal patterns in Serranus cabrilla habitat use in the NW Mediterranean revealed by acoustic telemetry. Mar Ecol Prog Ser 427:173-186

Blanco A, Deudero S, Box A (2009) Muscle and scale isotopic offset of three fish species in the Mediterranean Sea: Dentex dentex, Argyrosomus regius and Xyrichtys nova- cula. Rapid Commun Mass Spectrom 23:2321-2328

> Börger L, Dalziel BD, Fryxell JM (2008) Are there general mechanisms of animal home range behaviour? A review and prospects for future research. Ecol Lett 11:637-650

> Botsford LW, Micheli F, Hastings A (2003) Principles for the design of marine reserves. Ecol Appl 13:25-31

> Botsford LW, Brumbaugh DR, Grimes C, Kellner JB and others (2009) Connectivity, sustainability, and yield: bridging the gap between conventional fisheries management and marine protected areas. Rev Fish Biol Fish 19:69-95

Bowman A, Azzalini A (1997) Applied smoothing techniques for data analysis: the kernel approach with S-Plus illustrations. Oxford University Press, Oxford

Box A, Deudero S, Blanco A, Grau AM, Riera F (2010) Differences in $\delta 13 \mathrm{C}$ and $\delta 15 \mathrm{~N}$ stable isotopes in the pearly razorfish Xyrichtys novacula related to the sex, location and spawning period. J Fish Biol 76:2370-2381

Calenge C (2006) The package 'adehabitat' for the R software: a tool for the analysis of space and habitat use by animals. Ecol Model 197:516-519

Candi G, Castriota L, Andaloro F, Finoia MG, Marino G (2004) Reproductive cycle and sex inversion in razor fish, a protogynous labrid in the southern Mediterranean Sea. J Fish Biol 64:1498-1513

Cardinale M, Colloca F, Ardizzone GD (1997) Feeding ecology of Mediterranean razorfish Xyrichthys novacula in the Tyrrhenian Sea (Central Mediterranean Sea). J Appl Ichthyol 13:105-111

Cardinale M, Colloca F, Ardizzone GD (1998) Growth and reproduction of Xyrichthys novacula (Pisces: Labridae) in the Mediterranean Sea. Sci Mar 62:193-201

Castriota L, Grazia Finoia M, Andaloro F (2005a) Trophic interactions between Xyrichtys novacula (Labridae) and juvenile Pagrus pagrus (Sparidae) in the central Mediterranean Sea. Electronic J Ichthyol 1:54-60

Castriota L, Scarabello MP, Finoia MG, Sinopoli M, Andaloro F (2005b) Food and feeding habits of pearly razorfish, Xyrichtys novacula (Linnaeus, 1758), in the southern Tyrrhenian Sea: variation by sex and size. Environ Biol Fishes 72:123-133

> Francour P, Harmelin JG, Pollard D, Sartoretto S (2001) A review of marine protected areas in the northwestern Mediterranean region: siting, usage, zonation and management. Aquat Conserv 11:155-188

Froese R, Pauly DE (eds) (2005) FishBase. www.fishbase.org

Gaucherel C (2011) Wavelet analysis to detect regime shifts in animal movement. Computat Ecol Soft 1:69-85

> Hedger RD, Martin F, Dodson JJ, Hatin D, Caron F, Whoriskey FG (2008) The optimized interpolation of fish positions and speeds in an array of fixed acoustic receivers. ICES J Mar Sci 65:1248-1259

- Heupel MR, Semmens JM, Hobday AJ (2006) Automated acoustic tracking of aquatic animals: scales, design and deployment of listening station arrays. Mar Freshw Res $57: 1-13$

Hitt S, Pittman SJ, Nemeth RS (2011) Diel movements of fishes linked to benthic seascape structure in a Caribbean coral reef ecosystem. Mar Ecol Prog Ser 427: $275-291$

Jadot C, Ovidio M, Voss J (2002) Diel activity of Sarpa salpa (Sparidae) by ultrasonic telemetry in a Posidonia oceanica meadow of Corsica (Mediterranean Sea). Aquat Living Resour 15:343-350

Kaplan DM, Botsford LW, Jorgensen S (2006) Dispersal per recruit: an efficient method for assessing sustainability in 
marine reserve networks. Ecol Appl 16:2248-2263

Katsanevakis S (2005) Habitat use by the pearly razorfish, Xyrichtys novacula (Pisces: Labridae). Sci Mar 69: 223-229

Kaunda-Arara B, Rose GA (2004) Homing and site fidelity in the greasy grouper Epinephelus tauvina (Serranidae) within a marine protected area in coastal Kenya. Mar Ecol Prog Ser 277:245-251

Kramer DL, Chapman MR (1999) Implications of fish home range size and relocation for marine reserve function. Environ Biol Fishes 55:65-79

Krumme U (2009) Diel and tidal movements by fish and decapods linking tropical coastal ecosystems. In: Nagelkerken I (ed) Ecological connectivity among tropical coastal ecosystems. Springer, Dordrecht

Linde M, Palmer M (2008) Testing Allsop and West's size at sex change invariant within a fish species: a spurious ratio or a useful group descriptor? J Evol Biol 21:914-917

Maraun D, Kurths J, Holschneider M (2007) Nonstationary Gaussian processes in wavelet domain: synthesis, estimation, and significance testing. Phys Rev E Stat Nonlin Soft Matter Phys 75:016707

March D, Palmer M, Alós J, Grau A, Cardona F (2010) Shortterm residence, home range size and diel patterns of the painted comber Serranus scriba in a temperate marine reserve. Mar Ecol Prog Ser 400:195-206

Marconato A, And VT, Marin G (1995) The mating system of Xyrichthys novacula: sperm economy and fertilization success. J Fish Biol 47:292-301

Morales-Nin B, Moranta J, Garcia C, Tugores MP, Grau AM, Riera F, Cerda M (2005) The recreational fishery off Majorca Island (western Mediterranean): some implications for coastal resource management. ICES J Mar Sci 62:727-739

Morales-Nin B, Grau AM, Palmer M (2010) Managing coastal zone fisheries: a Mediterranean case study. Ocean Coast Manag 53:99-106

Palmer M, Balle S, March D, Alós J, Linde M (2011) Size estimation of circular home range from fish mark-

Editorial responsibility: Konstantinos Stergiou,

Thessaloniki, Greece release-(single)-recapture data: case study of a small labrid targeted by recreational fishing. Mar Ecol Prog Ser 430:87-97

$>$ Parsons D, Egli D (2005) Fish movement in a temperate marine reserve: new insights through application of acoustic tracking. Mar Technol Soc J 39:56-63

> Pauly D, Christensen V, Guenette S, Pitcher TJ and others (2002) Towards sustainability in world fisheries. Nature 418:689-695

> Payne NL, Gillanders BM, Webber DM, Semmens JM (2010) Interpreting diel activity patterns from acoustic telemetry: the need for controls. Mar Ecol Prog Ser 419:295-301

Percival D, Walden A (2000) Wavelet methods for time series analysis. Cambridge University Press, Cambridge

$>$ Rechisky EL, Wetherbee BM (2003) Short-term movements of juvenile and neonate sandbar sharks, Carcharhinus plumbeus, on their nursery grounds in Delaware Bay. Environ Biol Fishes 68:113-128

Simpfendorfer CA, Heupel MR, Hueter RE (2002) Estimation of short-term centers of activity from an array of omnidirectional hydrophones and its use in studying animal movements. Can J Fish Aquat Sci 59:23-32

Topping DT, Lowe CG, Caselle JE (2005) Home range and habitat utilization of adult California sheephead, Semicossyphus pulcher (Labridae), in a temperate no-take marine reserve. Mar Biol 147:301-311

> Tuya F, Boyra A, Sanchez-Jerez P, Haroun R (2005) Multivariate analysis of the bentho-demersal ichthyofauna along soft bottoms of the Eastern Atlantic: comparison between unvegetated substrates, seagrass meadows and sandy bottoms beneath sea-cage fish farms. Mar Biol 147:1229-1237

> Voegeli FA, Smale MJ, Webber DM, Andrade Y, O'Dor RK (2001) Ultrasonic telemetry, tracking and automated monitoring technology for sharks. Environ Biol Fishes 60: $267-281$

Zuur AF, Ieno EN, Walker N, Saveliev AA, Smith GM (2009) Mixed effects models and extensions in ecology with R. Springer, New York, NY

Submitted: December 14, 2011; Accepted: April 11, 2012 Proofs received from author(s): July 9, 2012 